\title{
Survey, Molecular Detection, and Characterization of Geminiviruses Associated with Cassava Mosaic Disease in Zambia
}

Rabson M. Mulenga, Zambia Agriculture Research Institute, Mount Makulu Central Research Station, Chilanga, Lusaka, Zambia; James P. Legg, International Institute of Tropical Agriculture, Dar es Salaam, Tanzania; Joseph Ndunguru, Mikocheni Agriculture Research Institute, Dar es Salaam, Tanzania; Douglas W. Miano and Eunice W. Mutitu, University of Nairobi, College of Agriculture and Veterinary Sciences, Department of Plant Sciences and Crop Protection, Kangemi, Nairobi, Kenya; Patrick C. Chikoti, Zambia Agriculture Research Institute, Mount Makulu Central Research Station; and O. J. Alabi, Department of Plant Pathology \& Microbiology, Texas A\&M AgriLife Research and Extension Center, Weslaco 78596

\begin{abstract}
Mulenga, R. M., Legg, J. P., Ndunguru, J., Chikoti, P. C., Miano, D. W., Mutitu, W. E., and Alabi, O. J. 2016. Survey, molecular detection, and characterization of geminiviruses associated with cassava mosaic disease in Zambia. Plant Dis. 100:1379-1387.

A survey was conducted from April to May 2014 in 214 farmers' fields located across six major cassava-producing provinces (Western, Northwestern, Northern, Luapula, Lusaka, and Eastern) of Zambia to determine the status of cassava mosaic disease (CMD) and the species diversity of associated cassava mosaic geminiviruses (CMG). Mean CMD incidence varied across all six provinces but was greatest in Lusaka Province $(81 \%)$ and least in Northern Province (44\%). Mean CMD severity varied slightly between provinces, ranging from 2.78 in Eastern Province to 3.00 in Northwestern Province. Polymerase chain reaction discrimination of 226 survey samples, coupled with complete DNA-A genome sequence analysis, revealed the presence of African cassava mosaic virus (ACMV), East African cassava mosaic

virus (EACMV), and East African cassava mosaic Malawi virus (EACMMV) as single or mixed infections of different proportions. Single-virus infections were predominant, occurring in $62.8 \%$ (ACMV), $5.8 \%$ (EACMMV), and 2.2\% (EACMV) of samples relative to mixedvirus infections, which occurred in $19.5 \%$ (ACMV + EACMMV), $0.4 \%$ $(\mathrm{ACMV}+\mathrm{EACMV})$, and $0.9 \%$ (ACMV + EACMV + EACMMV) of samples. Phylogenetic analysis revealed the segregation of virus isolates from Zambia into clades specific to ACMV, EACMV, and EACMMV, further confirming the presence of all three viruses in Zambia. The results point to a greater diversity of CMG across major cassava-growing provinces of Zambia and implicate contaminated cassava cuttings in disease spread.
\end{abstract}

Cassava (Manihot esculenta Crantz) is an important food crop for many countries in sub-Saharan Africa. The crop belongs to the genus Manihot (family Euphorbiaceae), which includes cultivated and noncultivated species. Cassava is not native to Africa and was introduced to the continent from South America by Portuguese traders about six centuries ago (Carter et al. 1995). Since then, it has become a dietary staple, especially in sub-Saharan Africa, where it is consumed by humans, utilized as livestock feed, and has gained traction as a potential source of biofuel and other industrial products in recent years. Cassava was probably introduced to Zambia via the Congo Basin, where the crop was already established by the early part of the 1650 s (Haggblade and Zulu 2003). Currently, it ranks as the second most important staple food crop in Zambia, after maize, and is consumed across the country in various fresh and processed forms. However, cassava average yield in Zambia (5.5 t/ha) is well below the African average of $12.3 \mathrm{t} / \mathrm{ha}$ (FAOSTAT 2013), mainly due to biotic and abiotic constraints, among which cassava mosaic disease (CMD) is considered to be one of the most important (Kaitisha 2003).

Viruses characterized from CMD-affected plants are collectively known as cassava mosaic geminiviruses (CMG). They belong to the genus Begomovirus (family Geminiviridae) and have characteristic twinned ("geminate") particles comprising two circular single-strand DNA genome segments (Harrison et al. 1977): the so-called DNA-A and DNA-B components. CMG, like other members of the genus Begomovirus, are transmitted by the whitefly vector Bemisia tabaci

Corresponding author: O. J. Alabi; E-mail: alabi@tamu.edu

*The $\boldsymbol{e}$-Xtra logo stands for "electronic extra" and indicates that one supplementary table is published online.

Accepted for publication 25 November 2015.

http://dx.doi.org/10.1094/PDIS-10-15-1170-RE

(C) 2016 The American Phytopathological Society
(Dubern 1994; Storey and Nichols 1938). Until recently, nine CMG were officially recognized by the International Committee on Taxonomy of Viruses (ICTV) and seven of them originated from and have been documented across Africa (Alabi et al. 2011). The "African" CMG are African cassava mosaic virus (ACMV; Stanley and Gay 1983), East African cassava mosaic virus (EACMV; Hong et al. 1993), East African cassava mosaic Cameroon virus (EACMCV; Fondong et al. 2000), East African cassava mosaic Malawi virus (EACMMV; Zhou et al. 1998), East African cassava mosaic Zanzibar virus (EACMZV; Maruthi et al. 2004), East African cassava mosaic Kenya virus (EACMKV; Bull et al. 2006), and South African cassava mosaic virus (Berrie et al. 1998). In the most recent revision of Begomovirus taxonomy by the Geminiviridae subgroup of the ICTV (Brown et al. 2015), the status of EACMCV was revised to that of an isolate of EACMV, thus reducing the number of African CMG to six. In addition, a new virus, Cassava mosaic Madagascar virus (Harimalala et al. 2012), was recently characterized from Madagascar while another novel tentative virus, African cassava mosaic Burkina Faso virus (Tiendrébéogo et al. 2012), is awaiting ratification by the ICTV. CMG occur as single- or mixed-virus infections and have been linked to devastating epidemics and severe yield losses (Legg et al. 2006; Owor et al. 2004; Thottappilly et al. 2003; Thresh et al. 1997) in most affected cassava fields in Africa. The occurrence of multiple CMG in sub-Saharan Africa and their presence as mixed-virus infections thus compounds the CMD situation due to the potential of begomoviruses to undergo genetic recombination or genome reassortments (Berrie et al. 2001), possibly leading to more severe disease, as was the case for the Uganda variant of EACMV (EACMV-UG) that triggered a severe CMD pandemic in East Africa in the 1990s (Otim-Nape et al. 1997).

The first documented occurrence of CMG in Zambia was in 1997, when ACMV and EACMV were reported based on serological diagnosis with a panel of discriminatory monoclonal antibodies developed by the Scottish Crop Research Institute, Invergowrie, 
Dundee, Scotland (Ogbe et al. 1997). The results were confirmed by a survey undertaken in 2009 and based on polymerase chain reaction (PCR) discrimination of field samples using primer pairs targeting ACMV, EACMV, and EACMV-UG (Chikoti et al. 2013). Given the fluid nature of CMD epidemics across sub-Saharan Africa, a periodic monitoring and reevaluation of the status of CMD and associated CMG in Zambia is necessary in order to document the species diversity of viruses associated with CMD in the country. Also, considering the limitations associated with the use of PCR alone for a conclusive identification of CMG in survey samples (Alabi et al. 2008; Thresh and Fargette 2001), it is essential to embark on sequence-based molecular characterization of CMG from Zambia. The current study presents the outcome of a country-wide CMD survey conducted across six major cassavaproducing provinces in Zambia from April to May 2014 and the analysis of the survey samples using PCR, cloning, and sequencing of partial and complete virus genome segments. The results provide definitive evidence for the presence of three CMG (ACMV, EACMV, and EACMMV) in CMD-affected cassava samples and their distribution as single- and mixed-virus infections in cassava fields in Zambia.

\section{Materials and Methods}

Survey routes, sample collection, and analysis. The surveys were conducted from April to May 2014 in six major cassava-growing provinces of Zambia; namely, Luapula, Lusaka, Northern, Eastern, Western, and Northwestern Provinces (Fig. 1A). As much as possible, survey routes were selected such that they encompassed areas of intense cassava production within each province. However, the between-field intervals varied from one province to the other depending on the density of cassava fields, such that a 10- to $15-\mathrm{km}$ interval was maintained for Northern, Luapula, Western, and Northwestern Provinces, where cassava fields were common, whereas the interval increased to 30 to $50 \mathrm{~km}$ for Eastern and Lusaka Provinces, where cassava fields were sparse. Thus, in total, 214 farmers' fields were visited during the survey (Table 1) and the coordinates of each field were recorded using a handheld global positioning system device (Garmin International Inc.). An overall CMD incidence per field was calculated based on visual assessment of 30 plants of the predominant cassava variety counted along two diagonals (15 plants per diagonal). For all 30 assessed plants, CMD infection was categorized as either cutting-borne (lowest first-formed leaves showing symptoms) or whitefly-borne (lowest first-formed leaves free from CMD symptoms), and the incidences of each were determined for all fields visited. Mean values for total CMD incidences and proportions of cutting-borne and whitefly-borne infections were calculated for each Province. The whitefly-borne infection values were transformed into multiple infection units (MIU) using the multiple infection transformation of Gregory (1948). CMD symptom severity was rated for the 30 plants assessed in each field based on the standard 1-to-5 scale, where 1 = no symptoms; 2 = mild chlorotic pattern over entire leaflets or mild distortion at the base of the leaflets; $3=$ moderate mosaic pattern throughout the leaf, with narrowing and distortion of the lower one-third of leaflets; $4=$ severe mosaic and distortion of two-thirds of the leaflets, with general reduction of leaf size; and $5=$ severe mosaic with distortion of the entire leaf (Terry 1975).
A

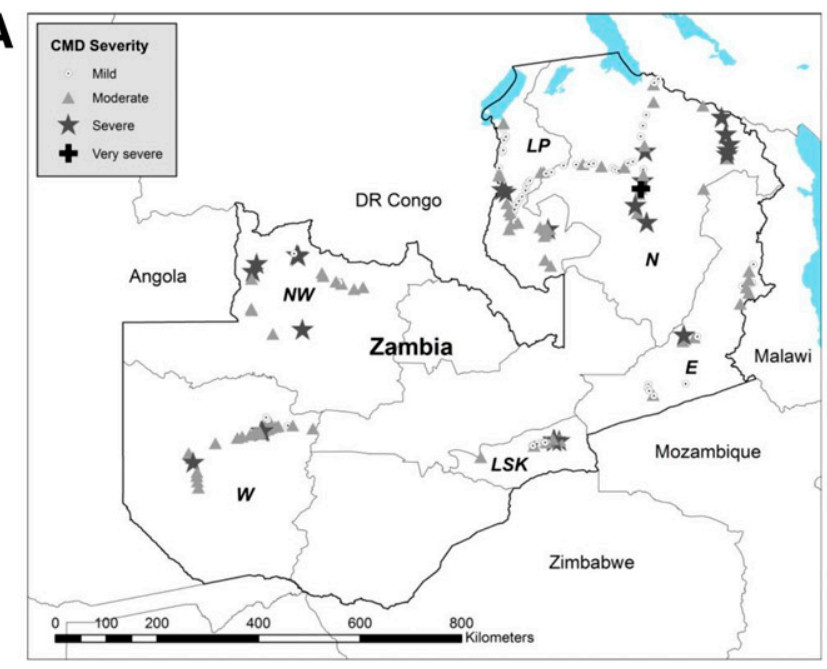

C

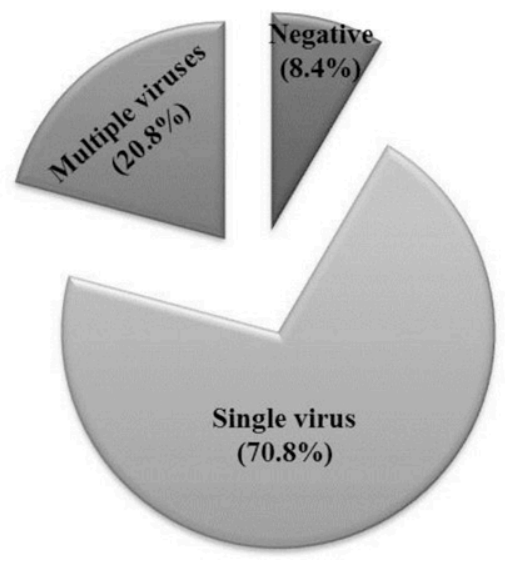

B

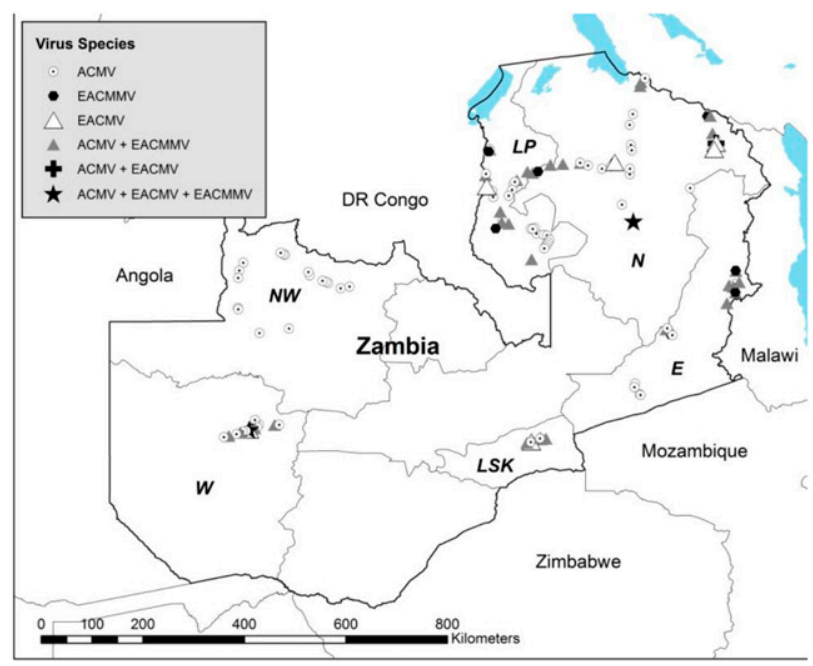

D

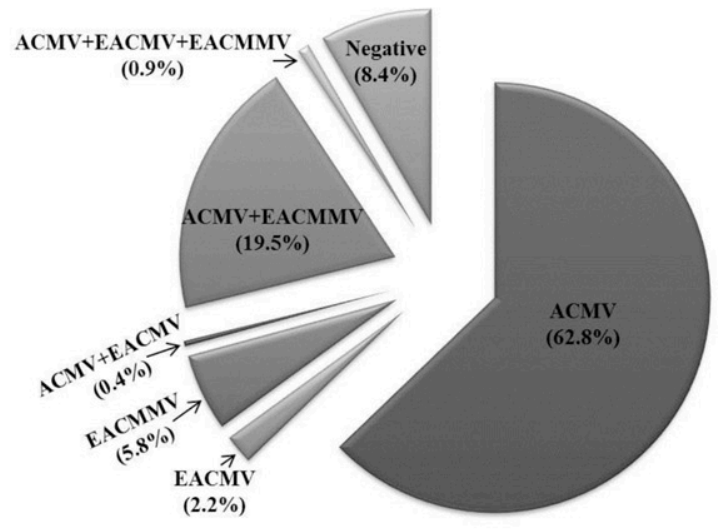

Fig. 1. Distribution of cassava farms in Zambia showing A, different levels of cassava mosaic disease (CMD) severity and B, profiles of associated cassava mosaic geminiviruses based on a diagnostic survey conducted during 2014. C, Relative proportions of single- and mixed-virus infections and D, virus combinations occurring in the survey samples are also shown. Province abbreviations are: LP, Luapula; LSK, Lusaka; N, Northern; E, Eastern; W, Western; and NW, Northwestern. 
Mean CMD severity was calculated for each of the most common varieties encountered, as well as each of the provinces.

A plant of the predominant cassava variety corresponding to the mean CMD severity score per field was selected for sampling, and symptomatic leaf tissue samples (Fig. 2) collected from each plant were preserved by storage in serviettes placed inside $50-\mathrm{ml}$ falcon tubes containing calcium chloride granules at room temperature. Twelve additional samples were collected from a few fields where

Table 1. Field dynamics of cassava mosaic disease (CMD) in Zambia based on a survey conducted across six major cassava-producing provinces ${ }^{\mathrm{a}}$

\begin{tabular}{|c|c|c|c|c|c|c|c|}
\hline \multirow[b]{2}{*}{ Province } & \multirow[b]{2}{*}{ Fields ${ }^{c}$} & \multirow[b]{2}{*}{ Samples $^{d}$} & \multirow[b]{2}{*}{$\mathrm{CCP}^{\mathrm{e}}$} & \multicolumn{3}{|c|}{ Mean CMD incidence $(\%)^{b}$} & \multirow[b]{2}{*}{ Severity ${ }^{\mathbf{f}}$} \\
\hline & & & & Total & Cutting & Whitefly & \\
\hline Western & 30 & 39 & 35 & 63.3 & 51.8 & $11.5(27.1)$ & 2.92 \\
\hline Northwestern & 17 & 18 & 18 & 58.0 & 55.2 & $2.8(6.5)$ & 3.00 \\
\hline Northern & 48 & 48 & 43 & 43.9 & 38.8 & $5.1(8.8)$ & 2.85 \\
\hline Luapula & 75 & 75 & 68 & 47.7 & 46.0 & $1.7(3.3)$ & 2.79 \\
\hline Lusaka & 20 & 20 & 20 & 80.9 & 78.3 & $2.6(13.0)$ & 2.85 \\
\hline Eastern & 24 & 26 & 23 & 48.8 & 44.5 & $4.3(8.1)$ & 2.78 \\
\hline Total (overall mean) & 214 & 226 & 207 & $(57.1)$ & $\ldots$ & $\ldots$ & $(2.87)$ \\
\hline
\end{tabular}

a In total, 226 leaf tissue samples were collected during the survey from 214 farmer's fields.

b Percentage of cutting-borne and whitefly-borne infections were calculated and multiple infection transformation values presented for the latter category (in parenthesis) based on Gregory (1948).

${ }^{c}$ Number of fields visited.

d Number of samples collected.

e Core coat protein $(\mathrm{CCP})$ positive.

${ }^{\mathrm{f}}$ Mean CMD severity scores are based on the standard 1-to-5 CMD scoring scale, where $1=$ no symptoms and $5=$ severe mosaic with distortion of the entire leaf (Terry 1975).
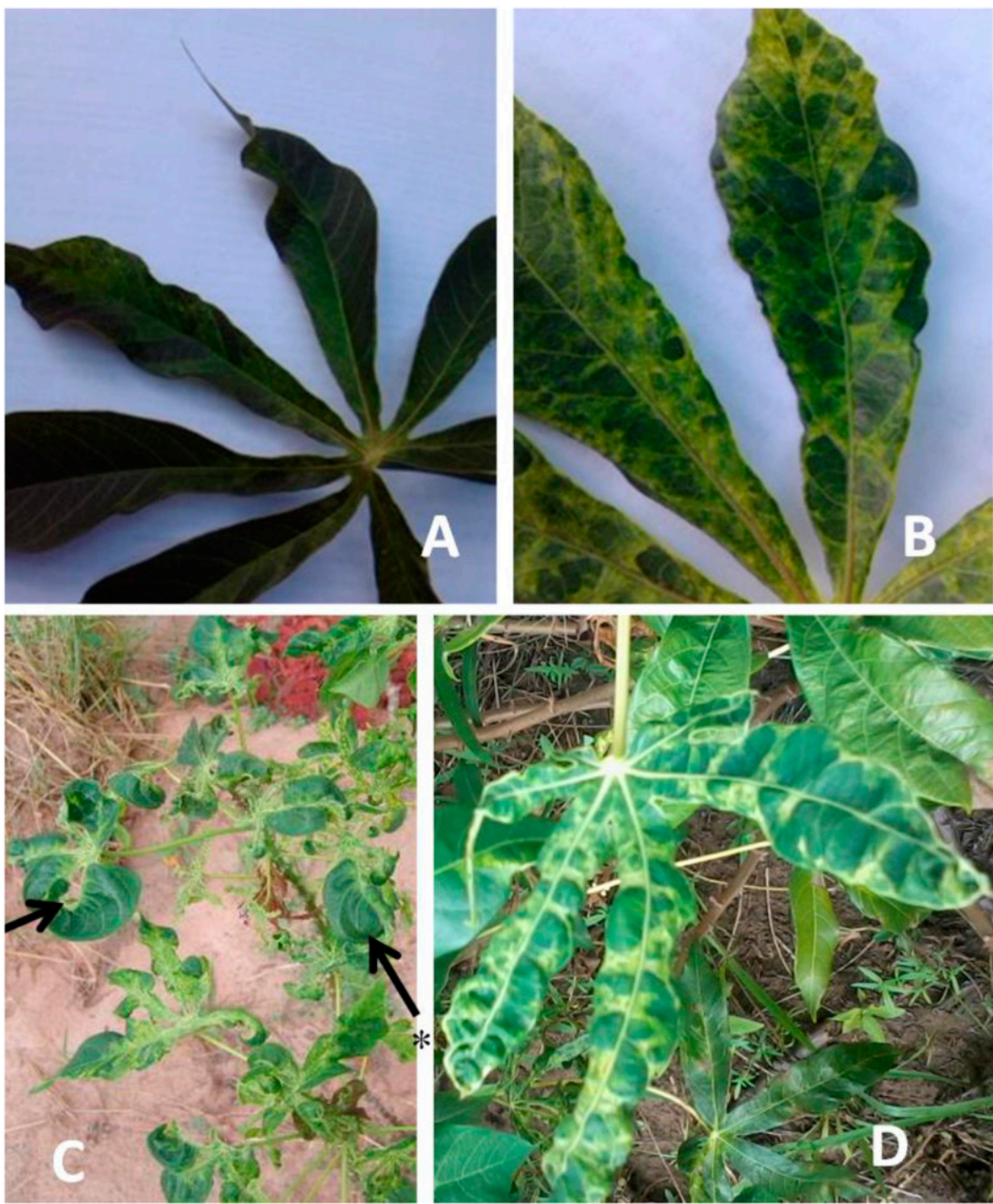

Fig. 2. Symptoms of cassava mosaic disease observed on naturally infected cassava plants across farmers' fields in Zambia. A, B, and D, Different patterns of mosaic symptoms were observed; $\mathbf{C}$ and $\mathbf{D}$, leaflets of affected plants may also become severely distorted; and $\mathbf{E}$, plants appearing defoliated.

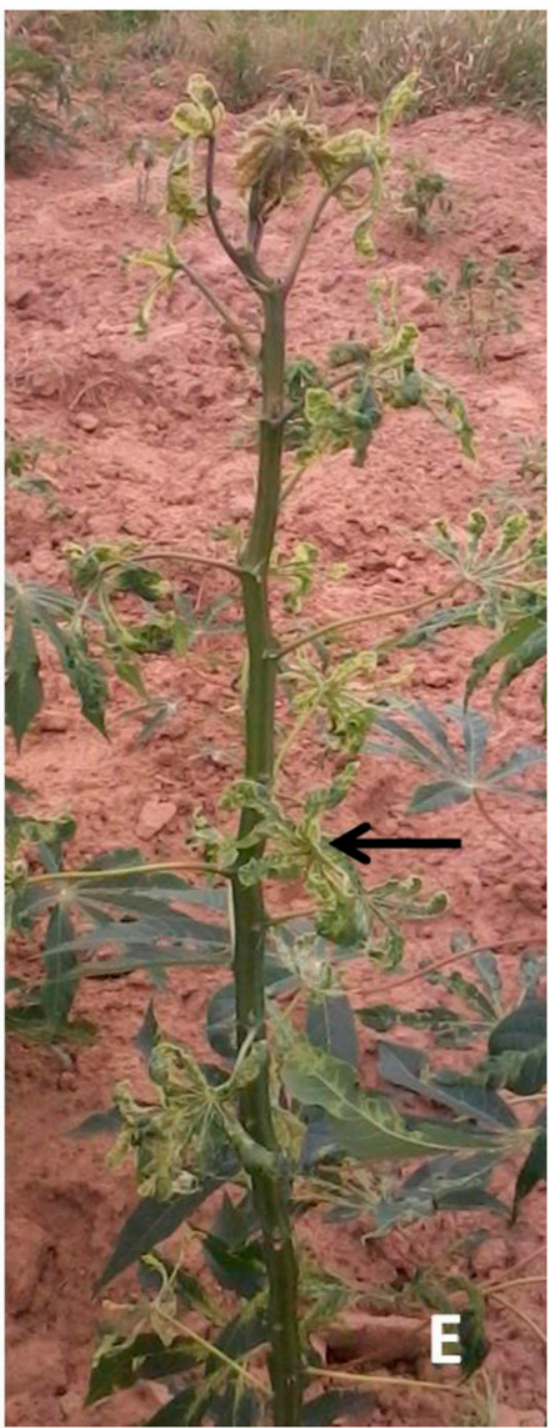


diverse CMD symptom types were observed, thus bringing the total number of samples collected during the survey to 226 (Table 1). The frequencies of each of the CMD severity scores were compiled for the 12 most commonly encountered varieties (having more than 100 plant stands scored during the survey), and their relative proportions between varieties were analyzed using the $\chi^{2}$ statistic (SigmaPlot 11.0; Systat Software).

Total nucleic acid extraction and PCR discrimination of survey samples. Total nucleic acids were extracted from $50 \mathrm{mg}$ of each cassava leaf tissue sample, as described by Dellaporta et al. (1983). The extracted nucleic acid was resuspended in $100 \mu \mathrm{l}$ of nuclease-free water, quantified using a SPECTROstar Nano microplate reader (BMG LABTECH), and analyzed for quality by agarose gel electrophoresis. Subsequently, DNA aliquots of smaller volumes per sample were stored at $-20^{\circ} \mathrm{C}$ until downstream analysis. PCR assays were performed for each sample in a total reaction volume of $25 \mu \mathrm{l}$ containing 1× DreamTaq Buffer (Life Technologies), $0.2 \mathrm{mM}$ each dNTP, $0.2 \mu \mathrm{M}$ each sense and antisense primers, $1.0 \mathrm{U}$ of DreamTaq DNA Polymerase, and approximately $20 \mathrm{ng}$ of total DNA. Each of the 226 survey samples was initially screened for the presence of CMG using the degenerate primer pair AV494/AC1048, capable of amplifying an approximately 550-bp product specific to the core coat protein $(\mathrm{CCP})$ region of several whitefly-transmitted geminiviruses (Wyatt and Brown 1996). Subsequently, total DNA templates from the subset of CCP-positive samples were screened with virus-specific primer pairs targeting ACMV, EACMV, EACMCV, EACMZV, and EACMMV (Aloyce et al. 2013). Reaction conditions were initial denaturation at $94^{\circ} \mathrm{C}$ for $3 \mathrm{~min}$, followed by 30 cycles of denaturation at $94^{\circ} \mathrm{C}$ for $40 \mathrm{~s}$, annealing at $55^{\circ} \mathrm{C}$ for $40 \mathrm{~s}$, and extension at $72^{\circ} \mathrm{C}$ for $40 \mathrm{~s}$. Following a final extension step at $72^{\circ} \mathrm{C}$ for $7 \mathrm{~min}$, amplification products were analyzed in a $1 \%$ agarose gel prestained with ethidium bromide $(10 \mathrm{mg} / \mathrm{ml})$ in $1 \times$ Tris-acetate-EDTA buffer and the gels were visualized using a Gel Doc XR System (Bio-Rad). Known negative and positive control samples were included in all assays, and an O'GeneRuler 1-kb DNA Ladder Plus (Life Technologies) was loaded as a size marker in parallel with the DNA amplicons.

Sequence determination and analysis of CCP-specific DNA fragments. To ascertain the specificity of the primers and also enable the molecular typing of virus isolates from Zambia, aliquots of total nucleic acids from a select number of representative PCR-positive samples were spotted on FTA Classic Cards (Whatman International Ltd.), air dried, then shipped under permit from the United States Department of Agriculture-Agricultural Research Service Plant Protection and Quarantine (P526P-14-04321) to the Texas A\&M AgriLife Research and Extension Center (TAMU AgiLife), Weslaco facility for further analysis. A modified version of a previously described simplified nucleic acid extraction protocol (Rowhani et al. 2000) was used for recovery of nucleic acids from the FTA Classic Cards. Briefly, three 2-mm discs excised from the spotted areas of the FTA Classic cards with the aid of a Harris punch were incubated in 1.5- $\mathrm{ml}$ microcentrifuge tubes containing $100 \mu \mathrm{l}$ of extraction buffer $\left(\mathrm{Na}_{2} \mathrm{CO}_{3}\right.$ at $1.59 \mathrm{~g} / \mathrm{liter}$, $\mathrm{NaHCO}_{3}$ at $2.93 \mathrm{~g} /$ liter [pH 9.6], 2\% PVP-40, 0.2\% bovine serum albumin, and $0.05 \%$ Tween 20 ) at room temperature for $1 \mathrm{~h}$ with periodic agitation. Thereafter, a $32-\mu 1$ aliquot of the DNA extract was mixed with $200 \mu \mathrm{l}$ of denaturing buffer $(0.1 \mathrm{M}$ glycine $[\mathrm{pH}$ 9.0 ], $50 \mathrm{mM} \mathrm{NaCl}, 1 \mathrm{mM}$ EDTA, and $0.5 \%$ TritonX-100, with $1 \%$ 2-mercaptoethanol added just before use) and the mixture was heated at $95^{\circ} \mathrm{C}$ for $10 \mathrm{~min}$ in a thermal cycler, followed by cooling for $5 \mathrm{~min}$ on ice. Using $2 \mu \mathrm{l}$ of denatured DNA eluates as template, PCR assays were performed on the samples with primers AV494 and AC1048 (Wyatt and Brown 1996), as described above. Amplified DNA fragments of the expected sizes were cloned individually into pCR2.1 TOPO-TA vector and transformed into One Shot TOP10 chemically competent Escherichia coli cells, according to manufacturer's protocol (Life Technologies). Transformed E. coli cells were screened by PCR using M13F and M13R primers and plasmid DNA isolated from cells carrying inserts of the correct size using the GenElute Plasmid Miniprep Kit (Sigma-Aldrich). At least two independent clones per DNA amplicon were subjected to Sanger sequencing in a commercial facility (ELIM BIOPHARM).

Following removal of cloning vector-specific sequences and oligonucleotides used for amplifying the cloned DNA fragments, the remaining sequences were subjected to BLASTN analysis (Altschul et al. 1990) to confirm their viral origin. Thereafter, sequences derived from the two independent clones per sample were considered as variants if they were found to share $<100 \%$ nucleotide sequence identity using the BioEdit sequence alignment editor (Hall 1999). The MUSCLE alignment program (http://www. ebi.ac.uk/Tools/msa/muscle/) was employed for generating multiple sequence alignments for the derived CCP sequences and aligned sequences used to determine the sequence identity matrix with the BioEdit program (Hall 1999) and for phylogenetic analysis using the maximum-likelihood algorithm of the molecular evolutionary genetics analysis software (MEGA, version 6) (Tamura et al. 2013). Corresponding sequences of published CMG were included in the analysis.

Complete genome characterization of CMG from Zambia. Total nucleic acids from a selected number of isolates representing the species diversity of CMG in Zambia, based on PCR discrimination of the survey samples, were subject to rolling cycle amplification (RCA) using the TempliPhi amplification Kit (GE Healthcare Life Sciences) essentially as described in the manufacturer's protocol. Aliquots of stock RCA products were archived on FTA Classic Cards and shipped under permit to the TAMU AgriLife, Weslaco, TX facility as described above for further analysis. The RCA products were recovered and processed using the same modified version of the simplified nucleic acid extraction protocol (Rowhani et al. 2000) described above. Aliquots $(2 \mu \mathrm{l})$ of the denatured RCA eluates were then subjected to PCR using a suite of published or newly designed primer pairs capable of amplifying complete DNA-A genome sequences of the target viruses (Supplementary Table S1). The approximately 2.8-kb DNA fragments obtained were cloned and sequenced as described earlier, and additional virus-specific primer pairs were designed and utilized for primer walking the plasmid DNA for each complete genome fragment. Multiple sequence alignments, pairwise sequence identity determination, and phylogenetic analysis of the complete DNA-A genome sequences were performed as described for the CCP-specific sequences.

\section{Results}

Field status and dynamics of CMD in Zambia. Typical CMD symptoms were observed across farmer's fields located in all six surveyed provinces (Fig. 2). The observed symptoms included mosaic patterns, leaf deformation, leaf reduction, leaf puckering, and overall stunted appearance of the affected plants (Fig. 2). Based on visual assessment of symptoms, mean CMD incidence varied by province and ranged from $44 \%$ for Northern Province to $81 \%$ for Lusaka Province, with an overall mean incidence of $57 \%$ for all six provinces (Table 1). CMD severity varied significantly among provinces $\left(\chi^{2}=249.77\right.$, $\mathrm{df}=10, P<0.001$ ), with the overall mean disease severity score being 2.87 for all six provinces, ranging from 2.78 for Eastern Province to 3.00 for Northwestern Province (Table 1). CMD severity also varied significantly across the 12 predominant varieties $\left(\chi^{2}=539.68, \mathrm{df}=22, P<0.001\right)$, with the landraces recording relatively higher mean severity scores compared with the improved cassava varieties (Table 2). Approximately $92 \%$ of the CMD infection across all the surveyed areas was cutting-borne while whitefly-borne infections accounted for approximately $8 \%$. There were clear differences between varieties with respect to the relative proportions of cutting- and whitefly-borne infections (Table 2). For instance, although varieties Kamuti and Kasonkoti had high incidences of cutting-borne infection and no whitefly-borne infection at all, others, such as Lingoma, Fote, and Nalumino, had moderate incidences of cuttingborne infection coupled with substantial amounts of whiteflyborne infection (Table 2). Province-level incidences of whitefly-borne infections were moderate to low based on transformed values to account for multiple infections (Table 1). 
CMG associated with CMD in Zambia. DNA amplicons of the expected size were obtained from $91.6 \%$ (207 of 226) of the survey samples with the CCP-specific primer pair, thus indicating that the majority of the survey samples were positive for at least one CMG. The remaining $8.4 \%$ (19 of 226) of samples were negative (Fig. 1C), possibly due to low virus concentrations in the plant or poor DNA quality. Further discrimination of the subset of 207 CCP-positive samples with species-specific primer pairs showed a preponderance of single (160 of 226 or $70.8 \%$ ) over multiple (47 of 226 or $20.8 \%$ ) virus infections in the samples (Fig. 1C). A breakdown of the virus profiles revealed single infection of ACMV to be by far the most frequent $(62.8 \%$ or 142 of 226$)$, followed by mixed infections of ACMV + EACMMV (19.5\% or 44 of 226), single infection of EACMMV (5.8\% or 13 of 226), single infection of EACMV (2.2\% or 5 of 226), mixed infections of all three viruses (i.e., ACMV + EACMV + EACMMV) in two samples (0.9\%), and mixed infection of ACMV + EACMV in only one (0.4\%) sample (Fig. 1D). None of the samples tested positive for EACMCV or EACMZV. Further analysis revealed that single infection of ACMV was predominant in all surveyed provinces, with the exception of Lusaka Province, where samples with mixed infection of ACMV + EACMMV were more frequent (Fig. 1B). Also, mixed-virus combinations of ACMV + EACMV or ACMV + EACMMV occurred in at least 1 sample from each of the provinces, with the exception of Northwestern Province, where all 18 samples had only single infection of ACMV (Fig. 1B). One sample each from Western and Northern Provinces had a mixture of all three viruses (Fig. 1B).

CCP genealogy of CMG from Zambia. In total, $38 \mathrm{CCP}$-specific DNA fragments derived from individual samples (Western $=5$, Northwestern $=4$, Northern $=11$, Luapula $=5$, Lusaka $=6$, and Eastern $=7$ ) were selected for cloning and sequencing, such that they covered the spectrum of virus species diversity detected in PCR analysis. A BLASTN analysis of the obtained sequences showed that they were virus specific and showed homology with corresponding sequences of ACMV, EACMV, and EACMMV available in GenBank, thus confirming results obtained by PCR. The two independent clones obtained for each of the 38 samples were compared with each other and both clones were considered as sequence variants when they shared $<100 \%$ nucleotide identity. The analysis resulted in 45 sequences (Western $=6$, Northwestern $=4$, Northern $=17$, Luapula $=5$, Lusaka $=6$, and Eastern $=7$ ), which were then used in a phylogenetic analysis along with corresponding sequences obtained from GenBank. All 45 sequences from Zambia (KT869078 to -118) clustered into three phylogroups representing ACMV, EACMV, and EACMMV along with representatives of related CMG from GenBank (Fig. 3A), further supporting their species classification obtained via BLASTN analysis of sequenced cloned amplicons. In all, 22 of the 45 CCP sequences (Western $=4$, Northwestern $=4$, Northern $=5$, Luapula $=4$, Lusaka $=2$, and Eastern $=3 ;$ KT869097 to -118) clustered into the ACMV-specific phylogroup (Fig. 3A) and shared 94 to $100 \%$ nucleotide identity with each other and 94 to $99 \%$ nucleotide identity with corresponding sequences of ACMV from GenBank. The EACMMV-specific phylogroup (Fig. 3A) consisted of $18 \mathrm{CCP}$ sequences from Zambia (Western $=1$, Northern $=8$, Luapula $=1$, Lusaka $=4$, and Eastern $=4$; KT869078 to -095), which shared 97 to $100 \%$ nucleotide identity with each other and 94 to $99 \%$ nucleotide identity with EACMMV sequences from GenBank. Five sequences derived from samples ZM-W377 (KT869096) from Western Province and ZM-N415 and ZM-N417 from Northern Province (KT869123 to -126) clustered into the phylogroup comprising isolates of EACMV, EACMKV, and EACMZV (Fig. 3A) and shared maximum (97\%) nucleotide identity with isolate EACMV-KE2[K48] from Kenya (AJ717542), and 95 to $96 \%$ nucleotide identity with other virus isolates within the phylogroup (Fig. 3A). These results provide further support for the occurrence of ACMV, EACMV, and EACMMV in cassava fields in Zambia and showed that the virus isolates from Zambia share high CCP identities with global isolates of corresponding viruses. However, although the relative clustering of ACMV-specific and EACMMV-specific CCP sequences derived from this study clearly supports their species designation, the clustering of several EACMV-like viruses in the same clade on the phylogenetic tree (Fig. 3A) makes their species classification inconclusive. Therefore, the results showed that the $\mathrm{CCP}$ region, though useful for molecular typing of CMG, is limited in its ability to generate a very robust phylogeny of EACMV-like viruses, thus necessitating complete genome characterization of the virus isolates.

Complete genome characterization of CMG from Zambia. In order to further characterize virus isolates from Zambia and to obtain a better resolution of the phylogeny of CMG present in cassava fields in the surveyed provinces, complete DNA-A genome segments were obtained from a select number of virus isolates. Two clones were sequenced per isolate to validate the results and to rule out possible misincorporation of spurious sequences generated via potential errors of PCR, cloning, and sequencing. The analysis involved 19 independent clones encompassing all three detected viruses (ACMV = 5 [KT869127 to -131], EACMV = 4 [KT869123 to -126], and EACMMV $=10$ [KT869119 to -122 and KP890349-354]) and were obtained from nine field isolates (ZM-LSK48, ZM-E69, ZM-E71, ZM-E74, ZM-N112, ZM-LP215, ZM-N415, ZM-N417, and ZM-N449). These sequence sets represent the first set of complete DNA-A genome sequences for ACMV, EACMV, and EACMMV from Zambia.

The complete DNA-A genomes obtained from five clones derived from two ACMV isolates (ZM-LP215 and ZM-N449) were determined to be 2,768 nucleotides (nt) each in length (KT869127 to -131). All five sequences shared 96 to $100 \%$ identity with each other and 95 to $96 \%$ identity with corresponding sequences of global ACMV isolates. Further analysis revealed varying lengths of the individual open reading frames (ORF) encoded by both virus isolates. For instance, whereas all five DNA-A clones derived from both ZM-LP215 and ZM-N449 encoded ORF AV2, AC1, AC2, and AC3 of the same length, they showed differences in the length of their encoded AV1, AC4, and AC5 ORF (data not shown). Overall, the complete DNA-A genomes of all five ACMV-specific sequences from Zambia appear to be more related to isolate West Kenyan 844 (J02057) on the phylogenetic tree of CMG (Fig. 3B).

The complete DNA-A genomes obtained from four clones from EACMV isolates (ZM-N415 and ZM-N417) were determined to be 2,801 to 2,802 nt in length (KT869123 to -126). All four sequences shared 95 to $100 \%$ identity with each other and 85 to $94 \%$ identity with corresponding sequences of five type EACMV isolates (Table 3) designated by the ICTV (Brown et al. 2015). In addition, the lengths of two of the replication-associated ORF (AC1 and $\mathrm{AC} 4)$ are conserved

Table 2. Proportions of cutting-borne versus whitefly-borne infections observed in the 12 most commonly encountered cassava varieties (landraces and improved) during a country-wide cassava mosaic disease (CMD) survey in $\mathrm{Zambia}^{\mathrm{a}}$

\begin{tabular}{lcccc}
\hline & \multicolumn{3}{c}{ Mean CMD incidence $(\boldsymbol{\%})$} & \\
\cline { 2 - 4 } Cassava variety $^{\mathbf{b}}$ & Total & Cutting & Whitefly & Mean CMD severity \\
\hline Bangweulu & 31.8 & 31.4 & 0.4 & 2.77 \\
Chilimabeni & 25.4 & 24.7 & 0.7 & 2.53 \\
Fote & 85.6 & 70.0 & 15.6 & 2.92 \\
Kabala & 60.1 & 53.9 & 6.2 & 2.58 \\
Kamuti & 83.3 & 83.3 & 0.0 & 2.82 \\
Kasonkoti & 73.3 & 73.3 & 0.0 & 2.16 \\
Kasonta & 63.4 & 61.7 & 1.7 & 2.53 \\
Katobamputa & 41.3 & 39.1 & 2.2 & 3.01 \\
Lingoma & 68.9 & 53.3 & 15.6 & 2.84 \\
Manyokola & 60.3 & 56.7 & 3.6 & 2.7 \\
Mwansanga & 73.4 & 71.7 & 1.7 & 2.98 \\
Nalumino & 69.2 & 57.7 & 11.5 & 2.79 \\
Overall mean & $\ldots$ & $\ldots$ & $\ldots$ & 2.72
\end{tabular}

a Mean CMD severity scores corresponding to each variety are also presented based on the scale developed by Terry (1975).

b Bangweulu, Manyokola, and Nalumino are improved varieties while others are landraces. 
for all four EACMV-specific sequences from Zambia, similar to those of isolates EACMV-KE (AJ717542) and EACMV-UG (AF126804) but different from those of isolates EACMV-CM (AF112354), EACMV-MW (JX473582), and EACMV-TZ (AY795983) (data not shown). Based on genome-wide and gene-specific pairwise comparisons (Table 3) as well as phylogenetic analysis (Fig. 3B), EACMV sequences from Zambia are more closely related to type isolate EACMV-KE2 [K48] from Kenya (AJ717542) than to other isolates.
The complete DNA-A genomes obtained from 10 clones derived from five EACMMV isolates (ZM-LSK48, ZM-E74, ZM-N112, ZM-E69, and ZM-E71) were determined to be 2,803 to 2,804 nt in length (KT869119 to -122 and KP890349 to -354). All 10 clones shared 99 to $100 \%$ identity among themselves and 98 to $99 \%$ identity with corresponding sequences of EACMMV isolates MH and MK from Malawi (AJ006459 and -60). Notably, EACMMV isolate ZM-LSK48 from Lusaka Province clustered separately from other
A

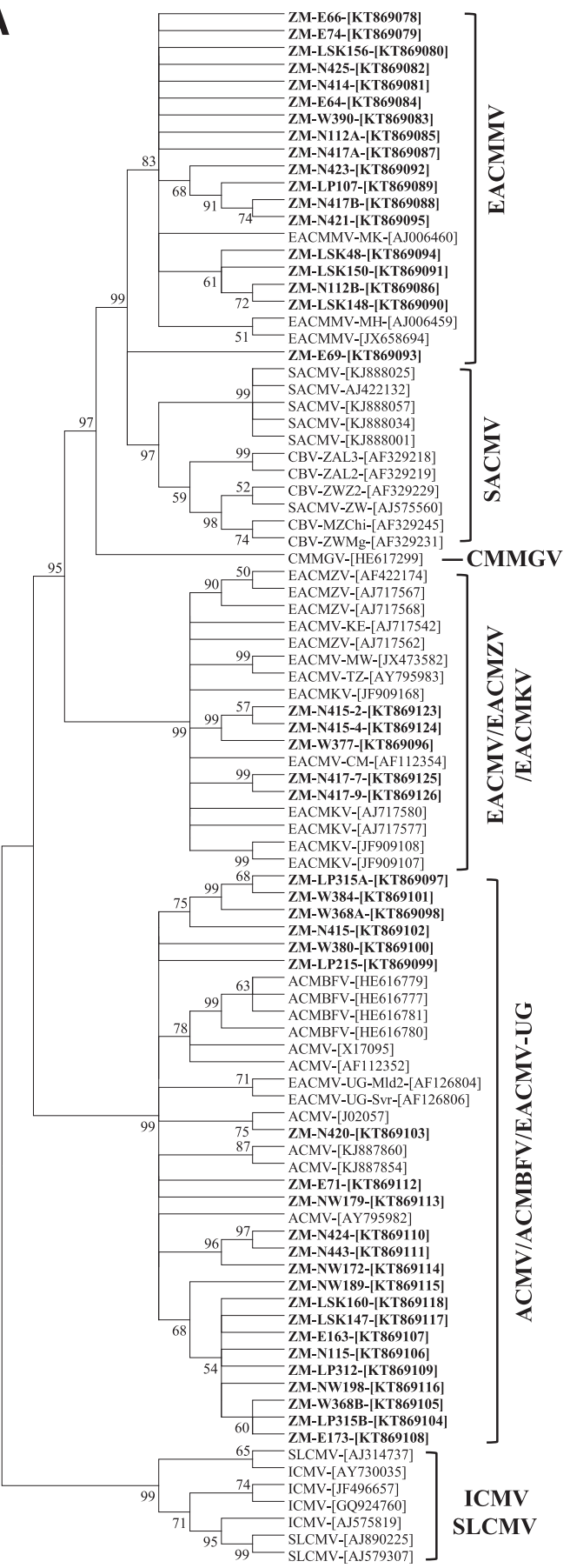

B

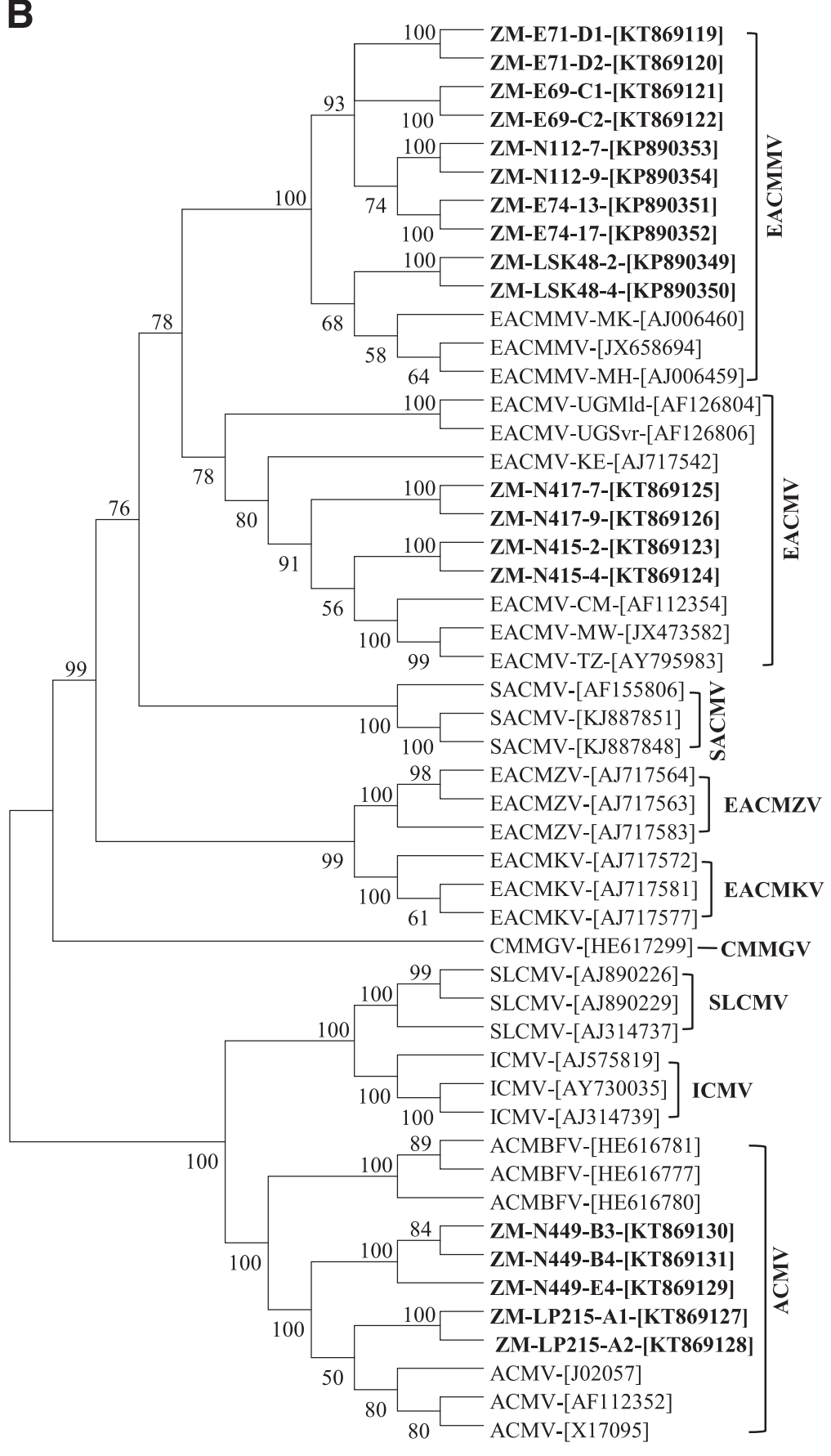

Fig. 3. Unrooted cladograms depicting the phylogenetic relationships between cassava mosaic geminiviruses from Zambia (in bold) and global virus isolates based on analysis of aligned nucleotide sequences specific to the A, core coat protein and B, complete DNA-A genome. Trees are based on analysis of 92 core coat protein ( 45 from Zambia and 47 from the GenBank) and 50 complete DNA-A genome (19 from Zambia and 31 from the GenBank) sequences. The bootstrap consensus tree was inferred from 1,000 replicates and branches corresponding to partitions reproduced in less than $50 \%$ bootstrap replicates were collapsed. ACMV = African cassava mosaic virus, EACMV $=$ East African cassava mosaic virus, EACMMV = East African cassava mosaic Malawi virus, EACMZV = East African cassava mosaic Zanzibar virus, EACMKV = East African cassava mosaic Kenya virus, SACMV = South African cassava mosaic virus, ICMV = Indian cassava mosaic virus, SLCMV = Sri Lankan cassava mosaic virus, CMMGV = Cassava mosaic Madagascar virus, and $A C M B F V=$ African cassava mosaic Burkina Faso virus. 
EACMMV isolates from Zambia (Fig. 3B), suggesting possible differences in the evolutionary paths of EACMMV isolates from Zambia. The results, along with a recent report (Mulenga et al. 2015), represent the first report of EACMMV from Zambia and evidence of its occurrence outside of Malawi.

\section{Discussion}

The results of this study showed the occurrence of ACMV, EACMV, and EACMMV in cassava fields in Zambia and their relative distribution as single- and mixed-virus infections across six major cassava-producing provinces. In previous studies, the occurrence of ACMV and EACMV was documented in Zambia based on serological (Ogbe et al. 1997) and PCR (Aloyce et al. 2013; Chikoti et al. 2013) diagnosis of survey samples. Thus, the current study provides definitive evidence for the occurrence of both viruses in Zambia. In addition to ACMV and EACMV, analysis of survey samples obtained in this study along with a recent report (Mulenga et al. 2015) revealed the occurrence of EACMMV, a previously unreported virus from Zambia. The fact that EACMMV was unreported from Zambia in previous surveys (Chikoti et al. 2013; Ogbe et al. 1997) is intriguing, given that the virus had been documented and characterized since 1998 in neighboring Malawi (Zhou et al. 1998). Although the Ogbe et al. (1997) study was conducted prior to the characterization of EACMMV and its recognition as a distinct virus species, the nondetection of the virus in a more recent survey (Chikoti et al. 2013) is likely due to the nature of the assay employed for discrimination of CMG in the survey samples. The apparent similarities between the survey locations sampled in the previous (Chikoti et al. 2013) and current study (Figs. 1A and B) provides further justification for drawing such an inference. Hence, it is plausible that several cassava tissue samples identified as EACMV positive in the Chikoti et al. (2013) study were EACMMV positive. The epidemiological implications of these results could extend beyond the geographical boundaries of Zambia. For instance, the occurrence of EACMMV at multiple locations in Luapula Province, neighboring the Democratic Republic of Congo (DRC), means that there is a strong likelihood that EACMMV also occurs in the Katanga Province of DRC. To date, no surveys of CMG have been conducted in this part of DRC.

For more than a decade, several studies have reported the design and evaluation of oligonucleotide primers for specific and generic detection of CMG in epidemiological studies, crop improvement, and phytosanitary programs using singleplex and multiplex formats (Alabi et al. 2011). The next logical step would be for the community of "Cassava Geminivirologists" to align resources and encourage periodic discussion on standardized assays and protocols for detection of CMG in epidemiological studies to ensure accuracy, repeatability, and reliability of results in independent studies. As new CMG and their recombinants are characterized, recommended standardized assays could be reevaluated, updated, and shared to ensure broad-spectrum coverage of all CMG during diagnostic surveys. In this regard, the complete genome sequences of virus isolates reported in this study provide an additional resource for enhancing understanding of the genetic relatedness of isolates of CMG across sub-Saharan African and deciphering plausible evolutionary scenarios, and for the development of more robust tools for reliable diagnosis of these economically important viruses.
The widespread distribution of EACMMV in single and mixed infections in samples collected from cassava fields located in spatially separated provinces of Zambia is indicative of an already established virus rather than a recent introduction. Although EACMMV was first described from Malawi (Zhou et al. 1998), the small number of fullgenome sequences available, particularly from Malawi, means that it is not currently possible to infer the likely geographical origin of this CMG species. Cassava landraces which are susceptible to CMD are prevalent across all six surveyed provinces (Table 2). The dominance of CMD-susceptible landraces among the 12 varieties (Table 2 ) indicates that farmers in Zambia depend largely on them as a source of planting material, and this farmer-to-farmer exchange could be behind the short-distance spread of CMG causing CMD in Zambia. The practice of farmer-to-farmer exchange of planting material is not peculiar to Zambia but has been reported in other sub-Saharan African countries (Harimalala et al. 2015; Ntawuruhunga et al. 2007; Sseruwagi et al. 1998) and could be attributed to farmers' lack of awareness of the risk posed by uncertified planting materials, the lack of ready access to virus-free planting material, farmers' preference for certain cassava landraces, or a combination of these factors. Although the inference about local spread is plausible from this survey, the means by which EACMMV is spread to all parts of Zambia points to factors other than the exchange of planting material by farmers. Although these factors were not established during the survey, spread by whitefly vectors and long-distance movements of infected planting material could both play important roles in the spread of CMG through Zambia. For whiteflies, studies have provided direct evidence for long-distance flights by whiteflies of up to $7 \mathrm{~km}$ (Cohen et al. 1988) as well as circumstantial evidence for long-distance spread of CMG by B. tabaci in East Africa (Legg 2010). However, recent data from cassava in Zambia suggest that B. tabaci populations are generally moderate to low (Chikoti et al. 2013). Therefore, there is a stronger case for long-distance spread through planting material. This is more so because cassava cultivation was strongly promoted in Zambia by different institutions from 1990 to 2010, and uncertified (and almost certainly infected) cassava cuttings were distributed to different parts of the country.

The higher incidence of mixed-virus infections obtained in this study (approximately $21 \%$ ) relative to the approximately $10 \%$ value reported earlier (Chikoti et al. 2013) points to a changing dynamic in the CMD situation in Zambia. Mixed infections of CMG have been shown to enhance symptom severity through synergistic interactions between coinfecting viruses (Berry and Rey 2001; Ogbe et al. 2003) and also provide opportunities for recombination events among different viruses, potentially leading to the emergence of new species (Pita et al. 2001). Interestingly, whereas the mean CMD incidence in Zambia showed a steady increase over time, from approximately $41 \%$ (Muimba-Kankolongo et al. 1997) to $52 \%$ (Chikoti et al. 2013) and 57\% (this study), mean disease severity across cassava-producing provinces has remained almost constant over the same period, in spite of the small increase in the proportion of mixed infections. A plausible explanation for this might be that CMD symptoms are somewhat modulated by prevailing environmental conditions across fields in Zambia, such that interactions between coinfecting viruses did not necessarily result in concomitant increases in disease severity. However, controlled inoculation studies

Table 3. Percent (\%) pairwise nucleotide/amino acid identities of East African cassava mosaic virus (EACMV)-specific sequences derived from Zambia with corresponding sequences of type isolates of the virus (Brown et al. 2015) ${ }^{\mathrm{a}}$

\begin{tabular}{|c|c|c|c|c|c|c|c|c|c|c|c|c|}
\hline \multirow[b]{2}{*}{ Comparisons } & \multicolumn{3}{|c|}{ ZM-N415-2 } & \multicolumn{3}{|c|}{ ZM-N415-4 } & \multicolumn{3}{|c|}{ ZM-N417-7 } & \multicolumn{3}{|c|}{ ZM-N417-9 } \\
\hline & DNA-A & AV1 & AC1 & DNA-A & AV1 & AC1 & DNA-A & AV1 & AC1 & DNA-A & AV1 & AC1 \\
\hline EACMV-CM & 86 & 95/97 & $86 / 90$ & 87 & $96 / 97$ & $86 / 90$ & 86 & $94 / 96$ & $87 / 90$ & 86 & $94 / 96$ & $87 / 91$ \\
\hline EACMV-MW & 85 & 95/94 & $86 / 84$ & 85 & $95 / 94$ & $86 / 84$ & 85 & 95/94 & $87 / 83$ & 85 & 95/94 & $87 / 84$ \\
\hline EACMV-TZ & 88 & 96/96 & $86 / 90$ & 88 & 96/96 & $86 / 90$ & 88 & 95/96 & $87 / 89$ & 88 & 95/96 & $88 / 90$ \\
\hline EACMV-UG & 92 & $85 / 89$ & 94/97 & 92 & $85 / 89$ & 94/97 & 92 & $84 / 89$ & $96 / 96$ & 92 & $84 / 89$ & 96/97 \\
\hline EACMV-KE & 94 & 97/99 & $92 / 95$ & 94 & 97/99 & $92 / 95$ & 94 & 97/99 & $92 / 94$ & 94 & 97/99 & 92/95 \\
\hline
\end{tabular}

${ }^{a}$ GenBank sequences: EACMV-CM (AF112354), EACMV-MW (JX473582), EACMV-TZ (AY795983), EACMV-UG (AF126804), and EACMV-KE (AJ717542). Sequences from Zambia: ZM-N415-2 (KT869123), ZM-N415-4 (KT869124), ZM-N417-7 (KT869125), and ZM-N417-9 (KT869126). 
in cassava or experimental host plants are needed to determine the effects of multiple infections of CMG occurring in Zambia toward a better understanding of interactions between coinfecting viruses (Rentería-Canett et al. 2011; Syller 2012). There was no evidence from the current study for the high levels of whitefly-borne CMD that have been associated with the pandemic of severe CMD in the Great Lakes region of East and Central Africa (Legg 1999; Otim-Nape et al. 1997). It was notable that CMD increments in MIU for each of the provinces in Zambia were all below 30 (Table 1), in contrast to values recorded for CMD pandemicaffected parts of Uganda in the 1990s, which ranged from 46 to 253 (Legg and Thresh 2000). As previously noted, the abundance of the whitefly vector in Zambia is relatively low (Chikoti et al. 2013) and much lower than values reported from pandemic-affected parts of East Africa (Legg et al. 2011). Thus, the observed difference in vector abundance seems to be the cause of the contrasting dynamics of CMD in the two situations.

From the management standpoint, it is hoped that, through focused education and outreach programs, cassava farmers in Zambia will realize the potential of improved varieties in combination with the use of "clean" planting materials for combating CMD in the country. In addition, current breeding efforts should continue to be tailored toward combining farmer- and consumer-preferred agronomic and culinary traits with enhanced resistance or tolerance to CMD to aid a better adoption of improved cassava varieties and further mitigate the impact of CMD on cassava production in Zambia.

The observed difference in the DNA-A genomes of the few virus isolates analyzed from Zambia relative to global virus isolates is interesting and worth investigating in future studies. Such differences might point to significant genetic variability among virus isolates from Zambia relative to global virus isolates. They may also suggest possible differences in the evolutionary paths of virus isolates from Zambia with and perhaps multiple routes of introduction for each of the three detected viruses. Therefore, the complete DNA-A genome sequences obtained in this study provide additional tools for conducting population genetic studies to decipher evolutionary scenarios and molecular aspects of the epidemiology of CMG on a regional basis.

In conclusion, this study represents the most comprehensive report, to date, of the status of CMD and its associated viruses in Zambia. Results from this study provide definitive evidence for the occurrence of three CMG (ACMV, EACMV, and EACMMV) in CMD-affected cassava plants in Zambia and points to an expanded geographical range of African CMG, with important phytosanitary consequences for international germplasm exchange involving Zambia. The virus distribution map generated in the study will help identify CMG cold and hot spots for use in cassava improvement programs and will facilitate the strategic deployment of improved planting materials with enhanced CMD resistance or tolerance to mitigate further spread of CMG. It is hoped that, in the long run, this will boost the livelihoods and incomes of the smallholder farmers for whom cassava is so vital.

\section{Acknowledgments}

Rabson M. Mulenga is a fellow of the Norman E. Borlaug Leadership Enhancement in Agriculture Program (Borlaug-LEAP) funded by USAID. This study was funded, in part, by a grant from the Bill and Melinda Gates Foundation awarded to Mikocheni Agricultural Research Institute, Tanzania and additional funding from Borlaug-LEAP. We thank T. Erik Mirkov and the Texas A\&M AgriLife Research \& Extension Center, Weslaco, for providing facility support through the duration of Mr. Mulenga's fellowship program; and M. Tembo, M. Chisola, M. Damaj, and L. Gregg for technical help.

\section{Literature Cited}

Alabi, O. J., Kumar, P. L., and Naidu, R. A. 2008. Multiplex PCR for the detection of African cassava mosaic virus and East African cassava mosaic Cameroon virus in cassava. J. Virol. Methods 154:111-120.

Alabi, O. J., Kumar, P. L., and Naidu, R. A. 2011. Cassava mosaic disease: A curse to food security in Sub-Saharan Africa. Online publication. APSnet Features. http://www.apsnet.org/publications/apsnetfeatures/Pages/cassava.aspx

Aloyce, R. C., Tairo, F., Ndunguru, J., Sseruwagi, P., and Rey, M. E. C. 2013. A single-tube duplex and multiplex PCR for simultaneous detection of four cassava mosaic begomovirus species in cassava plants. J. Virol. Methods 189:148-156.

Altschul, S. F., Gish, W., Miller, W., Myers, E. W., and Lipman, D. J. 1990. Basic local alignment search tool. J. Mol. Biol. 215:403-410.

Berrie, L. C., Palmer, K. E., Rybicki, E. P., and Rey, M. E. C. 1998. Molecular characterisation of a distinct South African cassava infecting geminivirus. Arch. Virol. 143:2253-2260.

Berrie, L. C., Rybicki, E. P., and Rey, M. E. C. 2001. Complete nucleotide sequence and host range of South African cassava mosaic virus: Further evidence for recombination amongst begomoviruses. J. Gen. Virol. 82:53-58.

Berry, S., and Rey, M. E. C. 2001. Molecular evidence for diverse populations of cassava infecting begomoviruses in Southern Africa. Arch. Virol. 146:17951802.

Brown, J. K., Zerbini, M., Navas-Castillo, J., Moriones, E., Ramos-Sobrinho, R., Silva, J. C. F., Fiallo-Olivé, E., Briddon, R. W., Hernández-Zepeda, C., Idris, A., Malathi, V. G., Martin, D. P., Rivera-Bustamante, R., Ueda, S., and Varsani, A. 2015. Revision of Begomovirus taxonomy based on pairwise sequence comparisons. Arch. Virol. 160:1593-1619.

Bull, S. E., Briddon, R. W., Sserubombwe, S., Ngugi, K., and Markham, P. G. 2006. Genetic diversity and phylography of cassava viruses in Kenya. J. Gen. Virol. 87:3053-3065.

Carter, S. E., Fresco, L. O., Jones, P. G., and Fairbairn, J. N. 1995. Introduction and Diffusion of Cassava in Africa. Res. Guide No. 49. IITA, Ibadan, Nigeria.

Chikoti, P. C., Ndunguru, J., Melis, R., Tairo, F., Shanahan, P., and Sseruwagi, P. 2013. Cassava mosaic disease and associated viruses in Zambia: Occurrence and distribution. Int. J. Pest Manage. 59:63-72.

Cohen, S., Kern, J., Harpaz, I., and Ben Joseph, R. 1988. Epidemiological studies of the tomato yellow leaf curl virus (TYLCV) in the Jordan Valley, Israel. Phytoparasitica 16:259-270.

Dellaporta, S. L., Wood, J., and Hicks, J. B. 1983. A plant DNA mini-preparation: Version II. Plant Mol. Biol. Rep. 1:19-21.

Dubern, J. 1994. Transmission of African cassava mosaic geminivirus by the whitefly (Bemisia tabaci). Trop. Sci. 34:82-91.

FAOSTAT. 2013. Food and Agriculture Organization (FAO) of the United Nations, Rome. Online publication. faostat.fao.org

Fondong, V. N., Pita, J. S., Rey, M. E. C., de Kochko, A., Beachy, R. N., and Fauquet, C. M. 2000. Evidence of synergism between African cassava mosaic virus and a new double-recombinant geminivirus infecting cassava in Cameroon. J. Gen. Virol. 81:287-297.

Gregory, P. H. 1948. The multiple infection transformation. Ann. Appl. Biol. 35: 412-417.

Haggblade, S., and Zulu, B. 2003. The recent cassava surge in Zambia and Malawi In: InWent, IFPRI, NEPAD, CTA Conf. Success Afr. Agric. Pretoria, South Africa.

Hall, T. A. 1999. BioEdit: A user-friendly biological sequence alignment editor and analysis program for Windows 95/98/NT. Nucleic Acids. Symp. Ser. 41: 95-98.

Harimalala, M., Chiroleu, F., Giraud-Carrier, C., Hoareau, M., Zinga, I., Randriamampianina, J. A., Velombola, S., Ranomenjanahary, S., Andrianjaka, A., Reynaud, B., Lefeuvre, P., and Lett, J.-M. 2015. Molecular epidemiology of cassava mosaic disease in Madagascar. Plant Pathol. 64:501-507.

Harimalala, M. A., Lefeuvre, P., de Bruyn, A., Tiendrebeogo, F., Hoareau, M., Villemot, J., Ranomenjanahary, S., Andrianjaka, A., Reynaud, B., and Lett, J.-M. 2012. A novel cassava-infecting begomovirus from Madagascar: Cassava mosaic Madagascar virus. Arch. Virol. 157:2027-2030.

Harrison, B. D., Barker, H., Bock, K. R., Guthrie, E. J., and Meredith, G. 1977. Plant viruses with circular single-stranded DNA. Nature 270:760-762.

Hong, Y. G., Robinson, D. J., and Harrison, B. D. 1993. Nucleotide sequence evidence for the occurrence of three distinct whitefly-transmitted geminiviruses in cassava. J. Gen. Virol. 74:2437-2443.

Kaitisha, G. C. 2003. Some virus diseases of crop plants in Zambia. Pages 317-333 in: Proc. Plant Virol. Sub-Saharan Africa. J. d'A. Hughes and B. O. Odu, eds. International Institute of Tropical Agriculture, Ibadan, Nigeria.

Legg, J. P. 1999. Emergence, spread and strategies for controlling the pandemic of cassava mosaic virus disease in east and central Africa. Crop Prot. 18:627-637.

Legg, J. P. 2010. Epidemiology of a whitefly-transmitted cassava mosaic geminivirus pandemic in Africa. Pages 233-257 in: Bemisia: Bionomics and Management of a Global Pest. P. A. Stansly and S. E. Naranjo, eds. Springer, Dordrecht, Heidelberg, London, New York.

Legg, J. P., Jeremiah, S. C., Obiero, H. M., Maruthi, M. N., Ndyetabula, I., OkaoOkuja, G., Bouwmeester, H., Bigirimana, S., Tata-Hangy, W., Gashaka, G., Mkamilo, G., Alicai, T., and Lava Kumar, P. 2011. Comparing the regional epidemiology of the cassava mosaic and cassava brown streak pandemics in Africa. Virus Res. 159:161-170.

Legg, J. P., Owor, B., Sseruwagi, P., and Ndunguru, J. 2006. Cassava mosaic virus disease in East and Central Africa: Epidemiology and management of a regional pandemic. Adv. Virus Res. 67:355-418.

Legg, J. P., and Thresh, J. M. 2000. Cassava mosaic virus disease in East Africa: A dynamic disease in a changing environment. Virus Res. 71: 135-149.

Maruthi, M. N., Seal, S., Colvin, J., Briddon, R. W., and Bull, S. E. 2004. East African cassava mosaic Zanzibar virus-A recombinant begomovirus species with a mild phenotype. Arch. Virol. 149:2365-2377. 
Muimba-Kankolongo, A., Chalwe, A., Sisupo, P., and Kanga, N. C. 1997. Distribution, prevalence, and outlook for control of cassava mosaic in Zambia. Roots 4:2-7.

Mulenga, M. R., Miano, D. W., Chikoti, P. C., Ndunguru, J., Legg, J. P., and Alabi, O. J. 2015. First report of East African cassava mosaic Malawi virus in plants affected by cassava mosaic disease in Zambia. Plant Dis. 99:1290.

Ndunguru, J., Legg, J. P., Aveling, T. A. S., Thompson, G., and Fauquet, C. M. 2005. Molecular biodiversity of cassava begomoviruses in Tanzania: Evolution of cassava geminiviruses in Africa and evidence for East Africa being a center of diversity of cassava geminiviruses. Virol. J. 2:21.

Ntawuruhunga, P., Okao-Okuja, G., Bembe, A., Obambi, M., Armand Mvila, J. C., and Legg, P. P. 2007. Incidence and severity of cassava mosaic disease in the Republic of Congo. Afr. J. Crop Sci. 15:1-9.

Ogbe, F. O., Atiri, G. I., Dixon, A. G. O., and Thottappilly, G. 2003. Serological and biological variations of African cassava mosaic virus in Nigeria. Ann. Appl. Biol. 143:203-213.

Ogbe, F. O., Legg, J., Raya, M. D., Muimba-Kankolongo, A., Theu, M. P., Kaitisha, G., Phiri, N. A., and Chalwe, A. 1997. Diagnostic survey of cassava mosaic viruses in Tanzania, Malawi and Zambia. Roots 4: 12-15.

Otim-Nape, G. W., Bua, A., Thresh, J. M., Baguma, Y., Ogwal, S., Semakula, G. N., Acola, G., Byabakama, B., and Martin, A. 1997. Page 65 in: Cassava Mosaic Viruses in Uganda: The Current Pandemic and Approaches to Control. Natural Resources Institute, Chatham, UK.

Owor, B., Legg, J. P., Okao-Okuja, G., Obonyo, R., and Ogenga-Latigo, M. W. 2004. The effect of cassava mosaic geminiviruses on symptom severity, growth and root yield of a cassava mosaic virus disease-susceptible cultivar in Uganda. Ann. Appl. Biol. 145:331-337.

Pita, J. S., Fondong, V. N., Sangare, A., Otim-Nape, G. W., Ogwal, S., and Fauquet, C. M. 2001. Recombination, pseudorecombination and synergism of geminiviruses are determinant keys to the epidemic of severe cassava mosaic disease in Uganda. J. Gen. Virol. 82:655-665.

Rentería-Canett, I., Xoconostle-Cázares, B., Ruiz-Medrano, R., and RiveraBustamante, R. F. 2011. Geminivirus mixed infection on pepper plants: Synergistic interaction between PHYVV and PepGMV. Virol. J. 8:104.

Rowhani, A., Biardi, L., Johnson, R., Saldarelli, P., Zhang, Y. P., Chin, J., and Green, M. 2000. Simplified sample preparation method and one-tube RTPCR for grapevine viruses. Page 82 in: Proc. XIII Meet. Int. Counc. Study of Virus-like Diseases of the Grapevine (ICVG), Adelaide, Australia.
Sseruwagi, P., Aritua, V., Otim-Nape, G. W., and Legg, J. 1998. Epidemic characteristics of cassava mosaic disease in Uganda: A 1998 update. Pages 11-17 in: Proc. Seventh Triennial Symp. Int. Soc. Trop. Root Crops Africa Branch, Cotonou, Benin.

Stanley, J., and Gay, M. R. 1983. Nucleotide sequence of cassava latent virus DNA. Nature 301:260-262.

Storey, H., and Nichols, R. F. W. 1938. Studies of the mosaic disease of cassava. Ann. Appl. Biol. 25:790-806.

Syller, J. 2012. Facilitative and antagonistic interactions between plant viruses in mixed infections. Mol. Plant Pathol. 13:204-216.

Tamura, K., Stecher, G., Peterson, D., Filipski, A., and Kumar, S. 2013. MEGA6: Molecular evolutionary genetics analysis version 6.0. Mol. Biol. Evol. 30: 2725-2729.

Terry, E. R. 1975. Description and evaluation of cassava mosaic disease in Africa. Pages 53-54 in: The International Exchange and Testing of Cassava Germplasm in Africa. E. R. Terry and R. Maclntyre, eds. IITA, Ibadan, Nigeria.

Thottappilly, G., Thresh, J. M., Calvert, L. A., and Winter, S. 2003. Cassava. Pages 107-165 in: Virus and Virus-Like Diseases of Major Crops in Developing Countries. G. Loebenstein and G. Thottappilly, eds. Kluwer Academic Publishers, Dordrecht, The Netherlands.

Thresh, J. M., and Fargette, D. 2001. The epidemiology of African plant viruses: Basic principles and concepts. Pages 61-111 in: Proc. Plant Virol. Sub-Saharan Africa. J. d'A Hughes and B. O. Odu, eds. International Institute of Tropical Agriculture, Ibadan, Nigeria.

Thresh, J. M., Otim-Nape, G. W., Legg, J. P., and Fargette, D. 1997. African cassava mosaic virus disease: The magnitude of the problem. Afr. J. Root Tuber Crops 2:13-19.

Tiendrébéogo, F., Lefeuvre, P., Hoareau, M., Harimalala, M. A., De Bruyn, A., Villemont, J., Traoré, V. S. E., Konaté, G., Hoareau, M., Traoré, A. S., Barro, N., Reynaud, B., Traoré, O., and Lett, J. M. 2012. Evolution of African cassava mosaic virus by recombination between bipartite and monopartite begomoviruses. J. Virol. 9:67.

Wyatt, S. D., and Brown, J. K. 1996. Detection of Subgroup III geminivirus isolates in leaf extracts by degenerate primers and polymerase chain reaction. Phytopathology 86:1288-1293.

Zhou, X., Robinson, D. J., and Harrison, B. D. 1998. Types of variation in DNA-A among isolates of East African cassava mosaic virus from Kenya, Malawi and Tanzania. J. Gen. Virol. 79:2835-2840. 